\title{
STRATEGIC PLANNING AT SPORTS ORGANIZATIONS
}

PhD Radovan Ilić, The sports and health high school - Belgrade

\begin{abstract}
Summary: The article defines the terminology of the strategic planning at sports organizations and puts an accent on its specifics. The first part explains what is planning and its functions in the strategic management in order to further put a light on the theoretic terminology of strategic planning and strategic management as well as to explain the relation between them. In the second part the phases of the planning in sports are revised as follows: (1) preplanning phase, (2) strategy formulating phase, (3) implementing strategy phase, and (4) evaluation and control of the planned assignments. The last part of the article is dedicated to concluding revisions. The conclusions from the researches of this complex problematic are given by number in a long-term view of the strategic planning in sport organizations.
\end{abstract}

Key words: strategy, management, planning, sports, organization, phase, process

\section{INTRODUCTION}

Planning is a phase (subsystem, function) of the management process where decisions are made on the purposes, the politics, the strategies, programmes and plans, which direct the activities in the sport organizations. Planning is a dynamic continuous process adapted by the sport organization and effects the environment in which it is functioning.

Planning is directing the sport organization based on past analyses, purposes evaluation, evaluation of the present situation and expecting future - choosing goals and the approaches for their realization through politics, strategies, programmes and plans. Through the plan decisions of purposes, politics, strategies, programmes and plans the entire activity of the sport organization is covered.

\section{TERMINOLOGY AND CONTENTS OF THE STRATEGY PLANNING AND STRATEGY MENAGEMENT}

\author{
1.1. Definition and function of \\ planning
}

One of the most important functions of management st the sport organization is planning. It is the ground for every mechanizm of management and acting, where politics, sports,vision, mission, purposes, strategy and tactics applied are bind together in order to obtain planning positions for the sport organization. Through planning the terms and conditions of the realization of the strategy and operative purposes of the organization are defined, and it could be deemed that planning is the initiative ground for the activities in management.

Based on past period analyses, the present positions and the vision for the future of the organization can be directed to future that being one of the ways of implementing plans. This is a choice of purposes and the approaches for their realization with the help of politics, strategies, programmes and plans. Having this function of management the choice of efficient direction for actions of adding, allocation, use and replacing of organization resources is made, and by "choosing" it is understood that the manager has a choice of one from many alternatives for making a decision. Consequently, we make the conclusion that the manager's making a decision for the best alternative is at the bases of planning process.

The main elements in the developing of the planning system for the organization's growth are the purposes, the strategies and the plans. Besides, we can state that this process starts with defining the purposes and revising the factors, which effect on their realization, followed by analyses of the alternative 
politics, strategies, programmes and plans, through which the purposes are performed in actions in an effective and efficient manner.

One of the most common definitions of planning defines it as ,,a process for specifying the purposes and the approaches for realizing them". (7) Nevertheless, the precission of this definition, many accept it as insufficient to explain the complexity of the planning function.

Some authors consider planning to be a phase in the management process and define it as "a subsystem of the managing process where a decision is made for the purposes, politics, strategies, programmes and plans, where the activities of the organization is directed". (4)

Planning is necessary because by making it an effect is produced on the adaptation of the organization to coming changes. The core of every planning process is to foresee the changes and to plan how they are to be realized through the planning action. The sport organization is prepared for planning in the moment when it has accepted that by planning it must perform the corresponding changes in purposes of progress the organization itself. It can be adequately reacted to changes in passive or active manner, respectively through passive or active adaptation. Only with the help of planning the external and the internal changes which the organization encounters in the process of purposes realization, the same can be modified and directed.

On account of all stated above, planning is one of the main functions of the management from which the other functions and works are derived and without which the sound management of an organization is impossible. Without planning the other functions can not be also performed, as well as the process of managing itself, for here is a sound interactive two-way relation with the rest of the management functions as organizing, developing human resources, managing and control.

After all said above it can be stated that planning is the most important function of management and also is the first phase of its process, to be the definition of the circumstances and the concrete planning assignments and to be a system for developing actions necessary for performing the purposes defined. Planning is a specific science discipline and a process which main system elements are purposes, strategies, programmes and plans. Planning is also a process for decision making for the adequate planning assignments.

As planning is a prime function of management, it is important also to provide the adequate circumstances for planning which depends on the attitude the organization has toward sports and also its role in community's life. The role of sports in community is best observed on bases of the general purposes research and the sport organization's mission. Therefore planning covers various decisions making on strategic, tactics and operative level and directed toward the purposes of the sport organization, and together with all other characteristics can be further derived that the planning is very systematic process.

Planning may be useful in many ways to the sport organization, which general purpose is establishing and sustaining positive relations between the organization and its environment. Planning in the organization provides possibilities for it to be proactive and independently to define the purposes for its existence, mission and directions for its activities, to independently effect on the outcome of its activities. Finally, the planning process may improve the financial results and the effective use of the resources in the organization, which in nowadays sport organizations are among the general organization's purposes, as well as to help developing team building.

Numerous problems have a sport organization that do not have adequate development plans for its activities. Such an organization is functioning at random grounds with insufficient time which is necessary to identify and counteract the future problems. Thus it is very possible to appear mean circumstances for the inefficient activity of the organization in the future. For all mentioned above, it can be concluded that planning is a necessary 
element which the management in the sport organization should be devoted to.

One of the reasons to start the planning process can be certain pressure on the sport organization in situations when things do not follow the right direction and when it is necessary to perform certain changes. Such pressure for changes may come from the internal or from the external environment of the organization itself, may be done by fan groups, sport community, owners and some times from the athletes themselves, the trainers or the managers. The organization under pressure is the reason and the planning is the outcome from this pressure. Planning has the task to provide a response to the changes in the environment or to perform the will of stakeholders for provoking adequate changes in the internal and external environment.

Factors for the pressure on sport organization, which have a planning process for result and entering in a planning cycle, may be divided to internal and external. Internal factors are, for example, new sport production, services and demands for the sport organization, new technology or changes in the structure of the organization. In terms of external factors we have in mind the changes in economic relations, changes in the legislation, new technologies and ideas presented on the market, the competitive enterprises, community changes, political situation and etc. When the sport organization is pressed to make changes it must react to the reason and the symptoms for pressure and finally it means that the organization must enter the process of strategic planning.

A fact that can not be ignored in the planning process is the time, because this is the way to define deadlines and terms for the performing of certain activities. Having in consideration this factor, the planning is divided to longterm, medium-term and short-term.

Long term planning is needed for the general orientation of the organization, its functions, structure and resources and is made for 10 to 20 years. It does not possess high level of uncertainty, but analyses external environment, affirms frames and development directions for the organization and to put the organization in the position in the context of these activities. Such an approach of long term planning is of specific importance because in a longer period the external factors have a bigger effect on the organization and on its development.

Medium term planning of development comes directly from the long term planning and refers to a period of 5 years. This time is longer than the four year period, the so-called Olympic cycle, which is taken for planning the sport results and for time measuring of the result forms of the biggest competition, although presently this cycle is decreased to two years after the more often competing among the best world and continental champions. The time less than two years can not comply with the principles for medium term planning, which is functional, directed to the segments and certain parts of the whole.

Short term planning is working out activities which are planned in the medium term plan. It refers to segments and parts of the whole in a shorter period. Short term planning covers the short term needs of propaganda, supplies of equipment and requisite, preparing the trainings for coming competition and other activities in the short period. It can be done yearly and operatively short term. For the yearly planning the so called operative planes are devised, and the important here is that the one-year period can be reduced to balance and account periods for calculating the working and sport assignments. The operative plans are devised for certain plan assignments and can be directed to working parts or activities of the organization, with duration of one to six months. Short term planning has a great importance for the organization, because the athletes and also the organization itself have numerous and various details and daily activities, which must be realized through plans and then performed.

\subsection{Strategic planning and strategic menagement}

The amount of the decisions and the activities, which are coming from these decisions and serve to formulate and perform the activities that lead to the right relation in sports and the sports organization and its environment through obtaining the organization's purposes are the strategic management in sports. Its 
general purpose is to improve the compatibility of the sport organization using the chances provided by the environment and by internal potential as it avoids dangers from external environment and as it removes internal weaknesses and disadvantages.

Strategy, politics and purpose are confirmed for the means of the establishing of a system in sports and for the functioning of the organization itself.

Da bi relizovala postavljanje ciljeve svaka sportska organizcija koja želi da bude efikasna i prepoznata kao pouzdan partner u sprtskim i poslovnim krugovima mora definisati svoju viziju, misiju, politiku i strategiju.

The beginning of every sports-working performance is a definition of a vision that is the direction for the future of each sport organizations. In order to realize the vision of a sport organization it is necessary that every single organizational part of it and all subsystems to have clear defined activities. The next step would be the defining of the individual activities in the subsystems and organizational parts in the sport system, which contain mission purposes.

Management by vision can help sports and the sport organization in the following five ways:

(1) encreasing the number of the sport performances and sport organization, (2) promoting the changes in sports and sport organization,

(3) securing the ground for strategic development of the sports, (4) mobilizing the athletes as individuals and providing for the tallents in sports, (5) to guarantee continuance in decision making.

Sport organization can not exist without two keys motivation facts - profit and vision. Vision is the generator for actions in sports and profit is the result of the competitive advantage performed by the sport organization and the sport as a whole in the process of working. Vision motivates the realization of the over average performances and the profit is the award for the obtained performances in the framework of the sport organization and the sports as a whole.
Mission is a certain complex of purposes and assignments that has support in the community values, and more precisely in sports results, followed by the profitability and the overall growth of the sport organization. Main element of the mission is grounded on the belief that the sport results and the provided sport-working services are to response to the needs of the consumers of the sport events, auditorium and fans, employees, owners and managers, media and the community as a whole.

Defining the mission of sports and the sport organization helps to confirm the main zone of interest of the sport-working system, the attainability of the intended activities and their prior values. After defying the mission a strategy is to be made followed by the working policies of the sport organization.

The appearance of the working process which is to define the strategic management is in all views a strategic planning. It is the general mean, mechanism and method for realizing the strategic management. Nevertheless, to a greater extend of cases these two concepts are equal, it should be stressed that the strategic management is a wider and more complex topic that is initially related to managing, while the strategic planning refers only to one of the managing functions. The two concepts are inevitably connected, complement one another and there is an interactivity between them because of which they can not exist and function.

Strategic planning is the condition for the further organizational planning. The following assignments are included in the framework of the strategic planning process: (1) defining the mission, (2) situation management SWOT analyses, (3) establishing purposes and directions in terms of the operative tactics, (4) developing strategies in consent to the operative tactics, and (5) monitoring of the plan.

Planning should be viewed as a continuous process, because the organizational, strategic, tactic and operative plans should be documents to which the organization's management constantly returns to, revises them and changes them in order to make them consistent to the eventual changes that appear or in cases when the purposes are met. Nevertheless, the 
strategic plans are made for four year and the operative plans - for one year, they are subject to evolution and evaluation as to relevance to the organization. Yearly revision of the operative plan may point out that certain modifications in the strategic priorities are needed as to the framework of the strategy plan because this provides an opportunity to the organization to react to changes, and the four-year cycle is too long, i.e. various changes are possible in the internal and external environment. Good plans may be dynamic, so the yearly revision of the operative plans should have an effect on the formulation of the strategy on yearly bases, not on four year grounds so that the strategic priorities should stay adequate and actual.

Developing a strategy and commencing certain planning actions are the consistent part of the successful management in sport organization. Strategies are plans working on widest possible scales that intend to provide interaction with the environment of the organization and for obtaining the long term purposes. Organizational strategic plan consists of formulating, choosing and announcing the strategy of the organization in a very wide context together with its mission and purposes.

\section{PHASES IN THE PLANNING PROCESS IN SPORTS}

Examining the planning as a process it can be stated that it is consisted of purposes, which the sport organization desires to perform in future, and the plans that are means devised to realize purposes. The adequate defining of the purposes and developing the plans lead to results desired and growth in the organization's efficiency and in the process itself is another important element - the mission of the organization.

The cycle of the planning defines the various assignments in management during the planning process and these tasks refer to the various elements, which may be as follows: (1) analyses of the current position, (2) confirming purposes, (3) examining various options, (4) detailed planning phase, (5) plan evaluation, (6) finalizing the planning process and (7) feed-back.
The effective planning process consists of more steps or phases which are grounded on confirming the common strategic direction and on defining the role of the strategic and the operative plans. In sport organizations there are four key phases, each of them consisting of various stages during the implementation of the planning process, these phases are as follows: (1) preplanning phase or preparing for planning, (2) formulating the strategy phase, (3) Implementation phase and (4) evaluation and control phase.

Each of these phases together with the stages is equally important for the final result and that is why to the functioning of the organization itself and the realizing of the purposes.

\subsection{Preplanning phase}

In this beginning phase of planning a research and describing of the present position must be initiated. This phase unites and combines the information from the yearly report and revision which contains statistic, financial and other data concerning the internal activities at the organization and the external influences to the organization. The key information of the organization's situation at this beginning of planning phase are getting from the yearly and several years reports. By revising and quantification of the sports and working results in the four-year or the yearly plan the assignments to perform must be examined, the level of performance must be confirmed and the reasons for non-performance of purposes are stated. The results from these aspects in future periods should be also stated and this can be shown by tables or detailed text with the important to the sport organization elements.

Because every organization works in a certain environment (external and internal) in which it realizes the purposes of its activities and this environment is a subject to situation analyses, analyses of the position and has the purpose to point out the level of compatibility of the sport organization. The attentive analyses of the situation in which the organization is, precedes the formulating of the efficient strategies for obtaining competitive advantages and enables the necessary prognoses making as a precondition to planning. 
When the analyses are made about the external and the internal environment in which the organization is functioning, as well as its competitiveness in certain circumstances and situations, a SWOT analyses is applied. By making the SWOT analyses the advantages of the organization are evaluated, i.e. $S-$ strength) and $W$ - weaknesses, together with the opportunities and chances $O-$ opportunities which come for the external environment as well as the $T$ - threats. The opportunities or chances are the circumstances in the environment which are favourable for improving the organization's positions refering to the competitors and the threats are circumstances in the environment which may put the organization in danger the competitive position of the organization.

SWOT analyses is used as a ground for the future development of the organization, but for the evaluation of the present abilities of the organization a comparison of the organization is to be made using benchmarking.

\subsection{Formulating the strategy phase}

Before the beginning of the performance at any sport organization, same applies to the new cycles beginning in the old organizations, the directions for future works should be set out. The answers to the problems about the future approaches in the organization, on the reasons for its existence, about the works in which it is involved, planning the directions of the activities, all that should be viewed in two initial elements of the strategic planning - the mission and the vision. From here come the rest of the issues to be defined - purposes, strategies and tactics.

Vision, as it is refering to a woder current activities range can be defined as ,mind picture" which actually and realistically presents the future of the organization. (1) Base of the vision, as an element of planning concerns the purpose of existing and sustaining of the organization (mission) to make the sense for the long term purposes and the initial grounds for choosing an adequate strategy.

Vision is the idealistic picture of the situation of the working and other activities at the organizations, which may be obtained in most favorable circumstances and which responses to the most optimistic intentions of the establishing body, the owner, the leader or the manager. The manager's vision on growth defines the current profile of the organization and also the future position of the organization. Vision gives the responses to the problems what are we presently and what would we like to be.

The vision in sports is equally a concept and politics and strategies, this is a dream about the sports even when it seems to be unattainable. Having in mind that the sport results are limited to the real human abilities, so is the sports vision limited to the manager's capacity. Vision in sports is a product made by all managers, most often the trainer-manager, it refers to individual athletes and sport teams with existing positions, sport values and projective value which can be obtained by planning actions. Vision covers the entire sport organization and its whole projection in the future, which is why it is only the idea for directing the organization which is to be altered in the process of confirming the organization's purposes.

Vision always has to be adequate and explicit, unidentified expressions are not suitable for involving the people in its realization. It can not be too wide or heavy to be performed. The most important aspect of the vision is the level to which it responses to the needs and the expectations of the employees. It should be taken into consideration that the difference between the successful and not successful visions is in the fact whether it is correctly realized in the practice. The explanation of the concept of the moving vision can be shown in the following steps: (1) announcing the explanation of the vision, (2) managing its importance through constant conversations and model making and (3) structure changes in the organization grounded on the vision.

Mission is the expression or the formal explanation of the nature of working activities at the organization and refers to the essence of the reasons for its existing. It responses to two questions: na pitranja: in what working field are we?, - the activities and why we are dealing with these works? Mission is the fundamental assignment of the organization's intentions for realizing its vision. (8) It is the 
logic extension of the vision process which should be redirected in real planning action and can be defined also as a description of the reasons for existing of an organization. Mission is the reason for existing and it should be feasible in reference to the organization's potential and the environment's condition.

Mission or the reason for existing of each organization contains also the mission which the sport as a category of the human activity has in it. This is an important element to be recognized by the sport managers while formulating the strategy and the organization's manifestation of mission and should not be subordinated to certain tendencies of equalizing the mission with money or profit. Mission is the self definition of the organization, the essence in which it is different to other organizations. As the mission is limited to the criteria of its formulating, it can not be moved in the framework of the general sports definition, its exclusive sport activities, and sport philosophy and also in the framework of the organization.

Planning should begin with defining announcing the mission because the mission is the reason why an organization exists. Announcing the mission is a clear and concise document that describes all working assignments at the sport organization to direct it and its functions and operations toward the most favourable opportunities. Announcing the mission should be brief, expressed in one sentence to be easily understood, to be worked on its realization individually and in team using the potential of the organization.

The announcement of the mission can be a very powerful mean to clear defining the reasons for existing of the sport organization, and the devotion to its formulating can be of key importance to its success. Mission helps management to focus on preserving or improving the competitiveness of the organization according to the others in the field or according to the customers of the sport services and products.

The final result that an organization desires to complete in future presents the purpose of the sport organization. The purposes are defined as a future situation referring to quantity and quality toward which the organization is directed and leads its long term activities. A purpose express the reason for existing of the organization and help to understand them, defines the needs that the organization should response in the future. All resources at the organization in various intensity and scales as to its functions are organizational purposes and they are the control positions in realizing plans. Based on vision and mission and in the framework of a certain period the long term may be defined as results that the organization has to achieve.

Having in mind that in sports and in sport organizations there is only one general purpose coming from their mission and refers to creating new and constant human and sport values, than the rest of them are concretely put to serve the development of the general purpose's realization. Their sources can be the following: (1) mission of sports, (2) the human freedom to be involved in sports, (3) achieving high sport results, (4) stability and working positions of the sport organization, (5) developing the expertise and creativity, (6) respecting the sport rivals and self respect, and (7) developing the standard and the improvement of the athlete and the expert.

\subsection{Strategy implementation phase}

After the phase of formulating the strategy the next phase is its implementation and the transition between the two of them is very sensible and can effect in difficulties during the transition period. This is the reason why the operative plans should be developed very well, namely those that define expenses and the additional plans related to concrete functions of the organization and are related to the strategic plans. It can be stated that the implementation phase depends on the development and the implementing of the operative plans and also the coherence between the internal and the external environment where the strategy is to be implemented.

As there are different risks that put into danger the implementation of the strategy planning the coordination among the members, actors, stakeholders as to plan documentation is very essential. The strategic plan that is formally accepted by the sport organization has more chances to overcome problems that are why 
the formulating of the plan must involve key investors in strategy implementation.

The development of the operative actions is related to operative-tactics actions that are confirmed by introducing measures and conditions for realizing plans and the development of alternative actions to be taken in various periods. This presumes revising the planning details and the phase is also called a detail planning phase. As a finalization of this stage of the strategy implementation the management should have a clear picture of the position of the sport organization, the purposes and the achievable options, one of them to be chosen. The detailed planning is a process of finding the most efficient approach to obtain the defined purpose.

During the process of detailed planning the key activities for purpose achieving are to be identified firs and if they are too complex - to divide them to a reduced number of smaller key activities. For each of them the way of performing is to be defined as well as the time, resources for the performance and on this base the expenses are calculated for each activity. Following action is the establishing of the priority activities depending on their importance in order to save time on assignments with less priority.

As purposes are the desired results, the plans are the means to produce the desired results. In cases when the purposes are part of the activities on strategic, tactic and operative level they can be less important without the definition of the approach for obtaining a purpose. The importance of planning becomes evident when there are more approaches to perform a purpose and the plans differ depending on the level of the organization and the number of repeating implementations.

Plan is the prescribed official document for the desired future state of the organization and in the same time it contains the elements of analyses of the present and the potential resources as a ground for the total growth of the organization. It is the way to foresee future status and present actions to reach the desired positions by the criteria for control of performing purposes and is the ground for decision making in everyday working process. Plan is the precise direction in a certain time and for a certain job assignment that should be performed and it expresses the desired direction of organization's development. There are four fundamental elements in the plan: (1) purposes that precisely draw future states, (2) actions that are the means for performing purposes, (3) resources that are usually limited during actions because of past determining of the resource quantities needed for the purpose performance (4) realizing the plan that is related to directing human resources toward realizing the plan.

On bases the organizational level in the organization the plans can be categorized as strategic, tactic and operative. Strategic plans contain details on the activities to be undertaken to achieve the strategic purposes, defined by the organization as mission, purposes and strategies. These are developed by the top management of the organization to cover relatively long period from 3 to 5 years. Tactic plans are devised to support the implementation of the strategy plan and for obtaining the tactic purposes. Operative plans are the support for the tactic plans and for obtaining the operative purposes and it is related to time frameworks of one year and even shorter. These are performed by the operative level managers.

\subsection{Evaluation and control of the planning assignments}

Plan is very important document that should be permanently used during the year in order to make decisions on important issues related to finances and the entire internal environment of the organization. When the plan is finalized and accepted at the beginning of its realization it should be regularly monitored and revised.

After working out the details of the plan, examinations of the phases should be made as to functioning, the expected affects - positive and negative results. It may occur that after the evaluation and comparison of the results the managers make a decision that the plan is not worth it to be implemented. When at this stage the evaluation of the plan is made, an opportunity is acquired to revise other options that were not taken into consideration before.

The methods for plan evaluation are numerous, among the most important are the 
analyses of the expenses/incomes/profits, PMI analyses, „Force Field" analyses, prognoses on the cash flow, analyses „Break Even Point “ and the risk analyses of the contingency planning. One of the approaches to test efficiency of the plan is the benčmarking test. The terminology bencmarking refers to the managing process on various levels of the organization activities in coherence to certain standards and the purpose is to give information for improving the decision making and evaluation processes that managers make to obtain better results of the activities. The two main types of benchmarking are the results focused on comparative information about the activities and the processes developing in the sport organization.

With accepting the plan the program ore the project are finalized. It may be useful to make an evaluation of the plan in reference to the quality, obtained quantities, the time that were needed to achieve what is planned and on what expenses. All these aspects should be revised in relation to the internal and external affects on the plan and thanks to that the management may come to conclusions needed for future planning.

\section{CONCLUSION}

Strategic planning is a development process and a process to analyze the mission of the sport organization, the overall purposes, general strategies and allocations of its resources. This is the part of the strategic management and in its bases it is long term defined, directed to problem solving. Precisely said the definition that most clearly describes the strategic planning is the process of defining the most important purposes of the sport organization as well as the strategy that helps to activate all disposable resources toward performing purposes process.

Strategic planning is developed and comes from the long term planning referring to the 5year period. The time is a little bit longer than the four-year period, the Olympic cycle that serves to plan sport results and time measuring the forms of the greatest competitions, though lately it is decreased to two years for the performances of the best world and continental champions. The time shorter than two years can not satisfy the demands of the principles of the strategic planning that is functional and directed toward the segments and the elements of the entire process.

Strategic planning in sport organizations is the precondition for further organizational planning. The following assignments are included in the framework of the strategic planning process: (1) defining the mission, (2) situation management SWOT analyses, (3) establishing purposes and directions in terms of the operative tactics, (4) developing strategies in consent to the operative tactics, and (5) monitoring of the plan.

Four key phases exist in the sport organizations; each contains different stages of performing the planning process. These are the following phases: (1) pre-planning or plan preparing, (2) strategy formulating phase, (3) strategy implementation phase and (4) evaluation and control phase.

\section{Literature}

1. Benuss, N. (1986): „Liders“, Harper and Row Publishers, New York

2. Đuričin D., Janošević S., Kaličanin Đ.,(2009): Menadžment $i$ strategija, četvrto, prerađeno i dopunjeno izdanje, Ekonomski fakultet Beograd, Beogra

3. Ilić, R. (2008): Pojam $i$ definisanje strategije u sportu, časopis Nova sportska praksa br.1,2, Visoka škola za sport, Beograd

4. Milisavljević, M., Todorović, J. (1990): Planiranje i rzvojna politika preduzeća, Savremena administracija, Beograd

5. Milić, Z., ,Menadžment ljudskih resursa u sportu“, Međunarodna viša stručna škola za preduzetništvo, Beograd

6. Nešić, M. (2008): Sport $i$ menadžment, Fakultet za sport i turizam, Novi Sad

7. Schermerhorn, J. ( 1996): Management, 5th end, John Wew, New York

8. Todorović, J. (1993): „Preduzetništvo $i$ menadžment", Direktor br. 3, Privredni pregled, Beograd

9. Tomić, M. (2001): Marketing u sportu, Astimbo, Beograd

10. Tomić, M. (2003): Menadžment u sportu, Minteko, Beograd

11. Tomić, M. (2007): Sportski menadžment, Data status, Beograd 